\title{
Review
}

\section{The Life Threatened Child and the Life Enhancing Clown: Towards a Model of Therapeutic Clowning}

\section{Donna Koller ${ }^{1}$ and Camilla Gryski ${ }^{2}$}

\author{
${ }^{1}$ Academic and Clinical Specialist, Department of Child Life, Hospital for Sick Children and ${ }^{2}$ Therapeutic Clown, \\ Therapeutic Clown Services, Toronto, Ontario, Canada
}

\begin{abstract}
In the last decade, there has been a rapid growth in the presence of clowns in hospitals, particularly in pediatric settings. The proliferation of clowns in health care settings has resulted in varying levels of professionalism and accountability. For this reason, there is a need to examine various forms of clowning, in particular therapeutic clowning in pediatric settings. The purpose of this article is to address what therapeutic clowning is and to describe the extent to which it can provide a complementary form of health care. In an attempt to apply theory to practice, the article will draw upon the experiences of a therapeutic clown within a pediatric setting while providing a historical and theoretical account of how clowns came to be in hospitals. Toward this end, a proposed model of therapeutic clowning will be offered which can be adapted for a variety of settings where children require specialized forms of play in order to enhance their coping, development and adjustment to life changes. Finally, current research on clowning in children's hospitals will be reviewed including a summary of findings from surveys administered at the Hospital for Sick Children.
\end{abstract}

Keywords: child life - clowning - complementary care - hospitalized child - pediatric psychosocial care - therapeutic play

\section{Introduction}

In the last decade, there has been a rapid growth in the presence of clowns in hospitals, particularly in pediatric settings. Many thousands of children are exposed to clowns during their hospitalization. For example, six clowns from the Therapeutic Clown Program at the Hospital for Sick Children (Sick Kids) in Toronto, Ontario, Canada, see an average of 20 children 2 days per week, for a total of over 10000 visits a year. Patients can range in age from infancy to adolescence.

The Theodora Foundation sponsors clowns in 82 hospitals on three continents, Europe, Africa and Asia. In the United States, 90 clown doctors from the Big Apple Circus Clown Care Units (CCU) provide 250000

For reprints and all correspondence: Donna Koller, Child Life Department, Hospital for Sick Children, 555 University Avenue, Toronto, ON M5G 1X8. Tel: 416-813-8211; Fax: 416-813-5364; E-mail: donna.koller@sickkids.ca bedside visits yearly. Australia has the Humour Foundation Clown Doctor Programs, South America its Doutores da Alegria (Doctors of Happiness) and France, Le Rire Médecin (Laughing Doctors). In addition, volunteer caring clowns visit countless hospitals and nursing homes, particularly in the United States and Canada.

This rapid expansion of clowns in health care settings has resulted in varying levels of professionalism and accountability. At their most professional, therapeutic clowns are respected complementary care providers who are able to articulate their role in the care of the patients as integral members of the health care team. At the other end of the spectrum, volunteer clowns, though wellintentioned, may be simply dressed-up people with little training and less understanding of the role and potential of the therapeutic clown. Therapeutic clowns in pediatric settings use gentle play and laughter to provide ill children with another avenue for emotional expression, 
control and social interaction during their hospitalization. The goal of therapeutic clowning is to minimize stress for patients and their families during hospitalization and treatment (1-3).

Since clowning in pediatric settings continues to grow, there is an urgent need to define the role of the therapeutic clown, particularly because this form of clowning can involve interactions with seriously ill or dying children. The purpose of this article is to address what therapeutic clowning is and to describe the extent to which it can provide a complementary form of health care. The aim is to offer an established model of therapeutic clowning upon which standards of practice can be developed and measured. In an attempt to apply theory to practice, the article will draw upon the experiences of a therapeutic clown within a pediatric setting while providing a historical and theoretical account of how clowns came to be in hospitals. Toward this end, a proposed model of therapeutic clowning will be offered which can be adapted for a variety of settings where children require specialized forms of play in order to enhance their coping, development and adjustment to life changes. Finally, current research on clowning in children's hospitals will be reviewed including a summary of findings from surveys administered at Sick Kids.

\section{Clowns as Healers}

Clown historian John Towsen (4) suggests that 'the clown's ability to evoke feelings of superiority in the spectator plays a hidden role in all clowning' (p. 206). Hoyle (5) calls clowns 'life-enhancing' and for Henderson (6), the clown is 'the embodiment of hope in the face of hopelessness, and possibility in the face of the impossible'.

However, the journey towards acceptance of therapeutic clowns by other health care professionals has not always been smooth, reflecting the ambivalent nature of the relationship between the clown and the society of which he or she is a part. Cline (7) offers a useful synthesis of this unsettled relationship. Speaking of the essence of the clown he says:

$\mathrm{He}$ is our scapegoat, "he who gets slapped," suffering every indignity that the human mind can conceive. He is our alter-ego, vicariously acting out the unspoken desires that we could never hope to act on in reality. He is our critic, piercing through our cultural hypocrisies with well-aimed barbs. And he is our healer, enabling us to laugh at the realities that could too easily make us weep. (p. 8)

Recounting a now-famous incident from the early days of the Big Apple Circus' Clown Care Unit, founder Michael Christensen tells how his clown character, Dr Stubs, once had a doctor come up to him and say,
" "Clowns don't belong in hospitals." I told him, "Neither do children."' (8, p. 37). 'Clowns here are you joking?' (9, p. 9) was the apparent response of a physician to Caroline Simonds, Artistic Director of France's Le Rire Médecin, upon hearing her request to provide clown doctor services to children in his hospital with lifethreatening illnesses. Yet the relationship between clowns and those in need of healing should not be so surprising. Historically and culturally, clowns have been associated with the well-being of society and the healing arts. It is believed that the hospital of Hippocrates kept troupes of players and clowns in the quadrangle, 'as the doctors of the day believed that mood influenced healing' (10, p. 202). The 12th century buffoon Rahere or Rayer, went on to found St Bartholomew's Priory and Hospital and Fair.

Clowns appear in the cultures of many First Nations peoples, functioning in ways similar to the saints, prophets and artists of the Western world (11). The sacred clowns of the Hopi serve as jesters, priests and shamans (12). This latter concept is taken up by Van Blerkom (13) who discusses the role of the Big Apple Circus CCU clowns in the context of shaman healers providing complementary therapy. To support her case, she cites the clowns' appearance, use of puppets, music, character and ritual, and their role as order-breakers.

Although many clowns have volunteered in hospitals as entertainers, and today's Caring Clowns continue to do so, the advent of the clown doctor and the therapeutic clown in health care settings can be traced back to 1986, when the two models in current hospital clowning originated independently. The following is a brief review of these models and their origins.

\section{Clown Doctors}

Michael Christensen, one of the founders of the Big Apple Circus, was asked to perform at an event at New York's Babies and Children's Hospital. Christensen, Dr Stubs, and his colleague Jeff Gordon presented a 20-min parody of the realities of hospital life to a delighted audience of patients, parents and staff. For Christensen, this was 'the most fulfilling twenty minutes of my professional career, and it was from that experience that the Clown Care Unit plan took root' (14).

All of the CCU clowns are professional artists who undergo a rigorous training program before working in the hospital. Their doctor characters evolved from the clown's natural relationship with authority figures: in the circus, the ringmaster; in the hospital, the doctor. It has also been suggested that the clown doctors' brightlycolored costumes and red noses paired with white coats help to make the 'institutional garment and the medical staff more "friendly" and less intimidating' (15, p. 1). In addition, clown doctors always work in pairs, to encourage creative performance, to free the child from 
pressure to participate, and to offer professional and emotional support (9). Simonds and Warren also suggest that a partner can indicate to a colleague the need to put on the brakes if a clown scenario is getting out of hand.

The CCU clowns use parody to demystify medicine and help children to cope with illness. Their 'clown medicine' includes red nose transplants, kitty cat scans and prescriptions for laughter. The CCU model has been both successful and influential. Clowns in programs from Paris to Montreal, Sao Paolo to Edinburgh as well as the clown doctors of the Theodora Children's Trust have adopted the doctor appellation and have donned white coats.

\section{Therapeutic Clowns within Child Life Programs}

In Canada, many programs follow the Therapeutic Clown/Child Life model. In 1986, professional clown Karen Ridd took her character Robo into the Children's Hospital of the Winnipeg Health Sciences Centre in Manitoba, Canada. Ridd joined the hospital's Child Life department, working both as a clown and a child life specialist. The aim of Child Life programs is to reduce the stress experienced by children and families while enhancing their abilities to cope effectively with stressful situations.

In her unpublished paper 'There Ought to Be Clowns', Ridd (2) sets the work of the clown in the context of humor and healing (i.e. Fry, Moody among others), the role of the clown in native societies, and the need for some creative order-breaking in the health care setting. She portrays the therapeutic clown as one who can change the child's perception of the hospital by her very presence while facilitating much needed stress release. Robo's ineptness allows the child to become the caregiver as well as the care-receiver, and enhances the child's sense of coping and control. Ridd portrays Robo as the child's friend, the encourager of play, imagination and creativity. Robo also provided support for patients during IV insertions and other procedures and starred as the patient in a series of short films designed to help children with medical procedures. Ridd summarizes Robo's work: 'Robo fulfills the clown's traditional role as healer by alleviating stress, raising spirits and abounding with love and joy' (p. 20).

Unlike clown doctors, therapeutic clowns usually work alone. It is not necessarily true that a single clown will put pressure on a child to respond as has been suggested in the literature (9). The therapeutic clown always asks permission before entering the room, and is trained to sensitively pick up cues from the child and family. The therapeutic clown interacts with the environment as well as the patient and family, and can use props or puppets as additional partners in play.

A single clown walking down the hospital corridor is out of place and vulnerable. The clown's vulnerability mirrors that of the child, who is also out of place in the health care environment, and who must ultimately, despite the support of family and friends, cope with his or her illness alone. In this respect, the clown and the child become allies. Cline (7) quotes Anthony Hippisley Coxe whose comments on the relationship between clowns and children are particularly applicable to the therapeutic clown: 'Children love him for a simpler reason. He expresses, loudly and eloquently, the bewilderment they feel when they find themselves in an adult world' (p. 19).

The Therapeutic Clown/Child Life Model has influenced programs across Canada, from Halifax to Vancouver. In 1993, Joan Barrington with the assistance of Ridd founded The Therapeutic Clown Program at The Hospital for Sick Children, Toronto, Canada. At Sick Kids, therapeutic clowns are considered staff of the Child Life department. As members of the larger health care team, therapeutic clowns provide a complementary form of care while sharing the goals and objectives of other professionals working with families.

Recently, efforts have been made to ensure that a level of professionalism and clinical standards exist among those who call themselves therapeutic clowns in Canada. Therapeutic clowns and clown doctors from across the country have joined together to form The Canadian Association of Therapeutic Clowns/L'Association Canadienne des Clowns Thérapeutiques (CATC/ACCT; 16). CATC/ACCT members agree to abide by the organization's Statement of Principles, Code of Ethics and By-Laws.

\section{Case Study Example: The Magical Music Box}

In order to further define the role of the therapeutic clown, the following case example illustrates three key concepts associated with this form of clowning: (i) empowerment, (ii) play and humor and (iii) supportive relationships.

This story is about an eight-year-old boy, a clown, and a game with a musical box:

At the time of this play, the child was comfortable with the clown, with whom he had played on and off for several months. His father was almost always present during the play, but usually chose not to be involved. The game with the music box had been developed and elaborated upon during several admissions. The tinkling notes played by the child always induced yawns and sleepiness in the clown, as her head slowly subsided onto her arms. When the music stopped, she sleepily raised her head and opened her eyes, only to subside again when the music began. The second or third time the child requested this game, he added the words, "You are getting very sleepy..." 
The clown obliged and added some realistic snores. "When I snap my fingers twice," he added, "you will peck like a chicken." The clown was required to become a chicken, a dog, and to sing Twinkle, Twinkle Little Star, which she did in her most clown-like off-tune voice. There was always an expectant silence before the clown, eyes closed, became transformed and launched into her new persona, followed by gales of laughter from both the child and his father. After about three transformations, the clown was allowed to wake up. The clown always left the room commenting on how refreshed she felt, and how restful it was to play with this child.

\section{Empowerment}

Clearly, in a child's relationship with a clown, in this play space, the rules are different. The clown is a master at manipulating status (3). A clown, clearly an adult, can be hypnotized by a music box, and a child can require her to do silly or incomprehensible things. The child feels superior, and is empowered: a very tidy turning of the tables for a patient who must cope with rules and regulations that could seem arbitrary and incomprehensible. Therefore, the continuing evolution of this play scenario encourages the child to take control in a situation where little control is possible.

This story also illustrates the vulnerability of the clown. The clown mask requires that we unmask, that we drop all our other masks and increase our sensitivity to others (17-19). Many clowns have commented on the necessity of enhanced antennae as they travel from room to room in the hospital. The experienced therapeutic clown will understand the careful balance he or she must achieve between true skills - whether in music, juggling or improvisation - and the need for qualities of innocence and the willingness to relinquish control to the child.

\section{Play and Humor}

The therapeutic clown, in her interaction with a child and his father, uses gentle play and humor to relieve the stress of treatment for cancer. Both therapeutic clowns and clown doctors, create opportunities for humor and laughter in the health care setting. Many claims have been made for the physiological and psychological benefits of humor. Dr John M. Driscoll Jr, quoted in a press release from the Big Apple Circus CCU that was published in The Hospital Clown Newsletter (20), makes a simple and effective statement:

'Ministering to sick children goes beyond medication and technology. Children don't understand these things, but they do understand the reassurance and fun that the $\mathrm{CCU}$ provides.
When a child begins to laugh, it means he's probably beginning to feel better. I see the clowns as healers' (p. 2).

The clown is a 'standing joke': she carries incongruity within her person (21, p. 29). The clown's presence in the hospital setting adds yet another layer of incongruity. Both therapeutic clowns and clown doctors benefit from the humor they create by simply being there. Therapeutic clowns are out of place altogether. Clown doctors create humor by joining together the idea of the clown and the idea of the doctor, a concept that Arthur Koestler (22) calls bisociation. Provine (23) discusses Schopenhauer's theory of laughter: 'Our success at incongruity detection is celebrated with laughter' (p. 15).

Central to the concept of fun, and an important prerequisite for the enjoyment of humor is a playful frame of mind (24). For the child in the hospital, the clown comes to embody the spirit of playfulness. When she is invited to step over the threshold, the space is changed and charged with possibility. The room suddenly becomes a playground, and the child is invited to come out and play.

\section{Supportive Relationship}

Building supportive relationships with patients and families is an essential part of the work of the therapeutic clown. As the music box story shows, the therapeutic clown and the child have played together over a period of several months, thereby establishing a trusting and supportive relationship. The child and his clown friend have developed ways of playing together that are comforting and predictable. The therapeutic clown will always bring certain toys and the play will often unfold along familiar paths. It may be said that the therapeutic clown exists only in a state of potential, waiting to be fully realized in a relationship with a child or young person.

Despite the fact that the therapeutic clown is a health care professional, he or she is perceived as coming not from the world of medicine but, as the family does, from the world of biography, the world of story (25). In these ways, with bubbles and giggles, with face paints and wind-ups and pure play silliness, meaningful and supportive relationships are forged between the child and the therapeutic clown. As a member of the health care team, the therapeutic clown is aware of the needs of other staff members as they work with the child. When it is appropriate, the clown can be a helpful distractive presence during medical procedures. Sourkes (26) suggests, 'For the child who lives under threat, the establishment of a secure therapeutic alliance is an intervention in and of itself' (p. 11).

As the therapeutic clown works to support the child through play, humor and empowering friendship, it is 
important that he or she keep in mind the fact that some children, young people and adults are afraid of clowns, whether because of the unfamiliarity of the make-up and costuming, because of unfortunate incidents with unskilled and insensitive clowns or because of the fairly recent appearance of 'evil clowns' in the media - all of which are given ample play on numerous Internet sites. In order to address some of these issues, therapeutic clowns tend to present with minimal make-up and costuming. A red nose and a hat, and a visually pleasing costume are enough to communicate the clown's identity. Therapeutic clowns learn how to approach babies, children, young people and their parents, and the staff, sensitively-for all of these are their clientele. A welltrained therapeutic clown will watch for cues and react instantly if any sense of unease is present. For example, simple techniques can often reassure a patient or family member: keeping an appropriate distance, initially avoiding eye-contact, and minimizing physical presence by crouching down or turning sideways. In addition to respecting a 'No' from a patient or parent and leaving for that day, a clown might at first play at the doorway or send bubbles into the room without ever entering. Many therapeutic clowns use music as a way to bridge the gap between clown and patient or parent. However, therapeutic clowning is not a popularity contest, and the clown must realize that on occasion, despite his or her best efforts and for whatever reasons, it is not possible to establish a therapeutic relationship with a patient. In this case, the clown gracefully withdraws, which action in itself can be empowering for the child or young person.

\section{Therapeutic Play and the Hospitalized Child}

Since children from all cultures play, the universality of play suggests it is an essential human function. Even in cultures where young children are expected to assume adult work responsibilities, literature provides examples of how children manage to integrate play activities into their daily work tasks (27). Through play, children learn how to handle the world and the social roles in it. For this reason, play becomes the predominant context in which children interface with the environment.

In child development literature, the use of play as a therapeutic intervention is extensively supported where the benefits are shown to be profound and wide-ranging. Following a meta-analysis of 800 studies, Fisher (28) concluded there was cogent evidence for the positive impact of play on child development. Play was found to significantly promote cognitive and social aspects of development and these effects were magnified when adults participated in play with children.

In pediatrics, research consistently cites the value of incorporating psychosocial care in children's health care (29). Particularly in a pediatric context, play provides a protective factor against developmental delays, regressive behaviors and emotional withdrawal (30-32). For this reason, Child Life programs are essentially hospital play programs and they have become an integral part of pediatric psychosocial care. These programs provide opportunities for hospitalized children to engage in play and to build therapeutic relationships based on these interactions.

Within this context, several varieties of play can occur. For example, children traumatized by medical experiences require opportunities for both non-directive and directive forms of play. For the most part, child life philosophy supports a child-centered approach where the adult follows the child's lead during play, opting for more non-directive than directive experiences. Non-directive forms of play allow children to safely explore their environment at a time when they may perceive physical challenges and vulnerability. In this way, hospitalized children are afforded the opportunity to take 'control' over their play experience in an environment where limited control is available to them (33-34).

Distinctions also need to be made between therapeutic play and play therapy. According to Oremland and Oremland (29), the focus of therapeutic play in contrast to play therapy is on the promotion of continuing 'normal development' and enabling children to respond more effectively to difficult situations such as health care experiences. Therapeutic play is developmentallysupportive and can include forms of enactments related to illness and hospitalization issues. Play therapy, on the other hand, addresses basic and persistent psychological issues associated with how a child may interact with his or her world. Therefore, therapeutic play, in a less structured way, focuses on spontaneous phenomena as the child engages in play to aid mastery of developmental milestones and critical events such as illness and hospitalization.

For the therapeutic clown within a Child Life program, play is predominantly defined as 'therapeutic' in that the clown takes the lead from the children, allowing them to become creative partners in the play experience. In particular, clowns are poised to create forms of play that tend to invite children to participate. The therapeutic clown assists children in the creation of safe and imaginary spaces, 'magic circles' of play (35, p. 19) within stressful hospital environments. Writing of the life-threatened child, Barbara Sourkes (26) comments on the child's particular need for safety: 'In a sea of uncertainty, the child's ongoing quest is to find a "safe place" within the storm' (p. 81). For this reason, the presence of the clowns in this setting is extremely powerful, for clowns can go where other adults may hesitate.

Imaginary, story-filled spaces allow the emergence of play forms that may function as therapeutic metaphors 
for the child. A game of Hide and Seek may allow the life-threatened child to test whether or not he or she would be missed (26). For example, the swelling and bursting of bubbles may speak to a child about the presence, growth or absence of a tumor (36). A magic trick that transforms a small object into a larger one and back again may allow a child to express feelings about a changing body image during treatment (37). As the play unfolds, the child's often profound concerns can be explored in a creative space that is both safe and comforting.

For the hospitalized child, playing with a therapeutic clown can provide opportunities for creative self expression as well as a welcome refuge from the stresses and challenges associated with illness, both of which support the notion that therapeutic play is indeed a form of complementary health care.

\section{Research on Clowning}

Despite the growing number of clown programs, there exists a paucity of research on clowning. In particular, research is needed to evaluate the impact of clowning in health care settings, and more specifically how therapeutic clowns play a role in the well-being of pediatric patients, their families and health care providers. Furthermore, the few studies that have been carried out have not been widely disseminated.

\section{Studies on 'Clown Therapy'}

Two pilot studies at Columbia University $(38,39)$, funded by the Richard and Hinda Rosenthal Center for Complementary and Alternative Medicine, focused on the effectiveness of clowns as distractive presences during cardiac catheterization and invasive procedures in a pediatric oncology day clinic. The research was conducted at Babies and Children's Hospital at ColumbiaPresbyterian Medical Center in New York. Researchers at the hospital collaborated with specially trained clowns to study the medical significance of 'clown therapy'. Clinical researchers from a variety of disciplines hypothesized that humorous distraction provided by the clowns would increase patient cooperation, ameliorate parental anxiety and decrease the need for sedation. Results showed that during cardiac catheterization there were significant decreases in observed child distress, in child self-reported distress and parent-rated child distress with the clowns present. As a result, physicians found the procedure significantly easier to perform with the clowns present. Clown interventions were non-toxic, did not cause respiratory depression, sedation or gastric upset. In addition, positive changes in the behavior and mood of health care providers were observed when the clowns were around. Long-term outcomes of the research included the successful implementation of clowns into medical settings in which there were no previous clown programs. In summary, this research showed how the presence of clowns can improve certain aspects of the pediatric experience. Authors call on the need for further research on the bio-psychological benefits of clowns with sick children in less frightening settings.

\section{Children's, Parents' and Staff Perspectives on Clowns in Pediatric Settings}

In a rare qualitative study, Aquino et al. (40) of Brazil asked children to describe their experiences with clown doctors. Twenty-seven pediatric patients between the ages of 4 and 12 participated in semi-structured individual interviews. Data analyses showed several important themes. Participants found the clowns to be humorous, which allowed the patients to laugh and be happy. In a review of the literature on laughter and humor, Bennett and Lengacher $(41,42)$ note that humor acts as a coping mechanism to reduce stress and psychological symptoms related to negative situations. For this reason, participants associated the work of the clown with one of healing, 'clowns helped kids to forget about their pain'. Some children noted that the playfulness of the clown allowed for distraction in that some children stopped crying during their medical procedures.

Similar findings were cited in a recent Italian study by Vagnoli et al. (43). The aim of their study was to investigate the effects of the presence of clowns on a child's pre-operative anxiety during the induction of anesthesia and on the parent who accompanied the child. The sample comprised 40 children (5-12 years of age) who had to undergo minor day surgery. They were assigned randomly to the clown group $(N=20)$ in which children were accompanied in the pre-operative room by a clown and a parent. The control group $(N=20)$ consisted of children being accompanied by one parent without the clown. The anxiety of the children and parents was measured using standardized scales. The clown group was significantly less anxious during induction when compared with the control group. A questionnaire was also developed for health care professionals in order to ascertain their opinions regarding the presence of clowns during induction. The questionnaire data for health care professionals indicated that the clowns were a benefit to the child, but the majority of staff was opposed to continuing the program because of perceived interference with the procedures of the operating room. This study provides a valuable contribution to the literature in that it validates the therapeutic benefits of the clown in a pediatric setting. Perhaps more importantly, the study identifies key issues for further exploration; namely, the significance of supportive health care teams for the development of innovative programs. Similar findings 
were identified in a study by Caprilli and Messeri (44) where some staff were hesitant to fully support a pet visiting program for fear it would interfere with hospital policies around safety. Therefore, a critical aspect associated with the development and sustainability of new forms of complementary medicine rests on whether health care staff are well-informed and collaborative efforts are maximized.

Clown programs at the Winnipeg Health Sciences Centre, British Columbia Children's Hospital, and the Children's Hospital of Wisconsin, among others have surveyed children, families and staff in their institutions. None of this research has been published. Other research $(45,46)$ examined therapeutic clowns and clown doctors and their programs rather than the specifics of their impact on the well-being of children.

\section{Evaluating the Therapeutic Clown Program at Sick Kids}

In 2004, at the Hospital for Sick Children (Sick Kids), the authors conducted a survey to address the impact of therapeutic clowning from the perspectives of pediatric health care professionals and parents of hospitalized children. Ethical approval was obtained by the hospital's Research Ethics Board. The purpose of the survey was 2-fold: (i) to provide an informal evaluation of the program and (ii) to obtain pilot data on the impact of therapeutic clowning with the objective of designing a future research study. Two quantitative surveys were created; one for staff and another for parents. Surveys were administered to staff and parents on five in-patient units. Both surveys addressed participants' understanding of the clown's role, how many clown visits per week were ideal, possible concerns regarding the program, to what extent they viewed clowns as part of the health care team and to what extent they valued the clown program. Questions provided participants with a variety of responses or they could indicate their own. Likert questions were also included. For example, participants could indicate the degree to which they viewed the therapeutic clown as part of the health care team. Survey questions were based on a careful review of existing literature on clowning in pediatric settings. The staff and parent surveys are included under Appendix 1 and 2 (published online as supplementary data).

A total of 330 surveys were randomly distributed to staff, of which, 143 (43\%) were completed and returned. Surveys were kept at the nurses' station and child life specialists assisted in the recruitment of staff by providing information at unit meetings. Of the 143 respondents, 123 (86\%) were nurses. Nurses included: bedside nurses, clinical nurse practitioners, nurse managers and discharge planners. Additional staff comprised: unit clerks (7\%), child life specialists $(2 \%)$, social workers $(2 \%)$, occupational therapists $(2 \%)$ and physiotherapists $(1 \%)$. The greatest number of completed surveys was received from in-patient units where the role of the therapeutic clown was established, usually over a 2-year period.

Because some parents would be unfamiliar with the clown program, parent surveys were administered after a clown visit was made with a child. For each in-patient unit, a research assistant accompanied a clown as visits were made. Following a play session, the research assistant would inform the parent of the survey. Parents were told that the purpose of the survey was to help evaluate the clown program. They were also explained that participation was voluntary and that the surveys were anonymous in that no identifying information was asked. Only two parents refused participation; one based on limited English language skills and another for a lack of knowledge about the clown program. A total of 51 parent surveys were completed.

Frequencies were calculated on the raw data for each of the questions on the surveys. In terms of how staff viewed the work of the therapeutic clown, $88 \%$ believed it was to engage children in play. Almost half of the staff participants $(47 \%)$ viewed the clowns as supportive of their work. For the most part, staff were comfortable with two clown visits per week on their units. With regard to the question: 'are there things about the therapeutic clown that concern you?' the vast majority $(85 \%)$ had no concerns at all. Some staff indicated concerns regarding the fear of clowns, both from the staff and child's perspectives. Other issues addressed how clowns decide on which children to visit and that clowns were predominantly beneficial for younger children. A large number of staff $(76 \%)$ also believed that clowns were a part of the health care team (i.e. definitely-45\%, and very much so- $31 \%$ ). Similarly, $93 \%$ of staff believed that the clown program was beneficial to the hospital (i.e. definitely $-34 \%$, very much so- $59 \%$ ).

For parents, $88 \%$ viewed the role of the clown as making children happy. Only $22 \%$ of parents believed that the role of the clown was to help other professionals with the children. The majority of parents $(80 \%)$ enjoyed the clown visits, and believed their children did too (i.e. always-78\%). Ninety-four percent of parents acknowledged that their child was happier following a clown visit. In contrast to staff, the majority of parents $(51 \%)$ believed they wanted more clown visits and $86 \%$ believed that the clown program was 'very good' for the hospital.

Although only frequency data were compiled, the results of these surveys show strong support for the role of the therapeutic clown. However, clear outcomes cannot be assessed from descriptive data obtained from one survey. Additional statistical analyses (i.e. inferential statistics) from a comprehensive study could yield a more in-depth examination of therapeutic clowning in pediatric settings. Because this area of research remains virtually unexplored, a mixed method approach may be 
most suitable. For example, qualitative interviews and focus groups could provide the basis upon which to create standardized measures that reflect key aspects of therapeutic clowning. Emerging themes from qualitative data may identify critical areas relating to child outcomes such as the impact of therapeutic clowning on pediatric anxiety.

In the meantime, the growing number of therapeutic clown programs suggests that the field is rapidly expanding despite a lack of clinical standardization and research. Additional research is necessary for the development of evidence-based practice, a prerequisite for establishing legitimacy within ever-changing and demanding health care environments. Future research must also include the perspectives and experiences of pediatric patients. The relationship between a therapeutic clown and a hospitalized child is complex, laden with inherent meanings and perceived benefits. Having children participate in such research as primary stakeholders assures them a voice in decision making around various aspects of their psychosocial and complementary forms of health care, which include opportunities for therapeutic play.

\section{Conclusions}

The purpose of this article was to elucidate the role of the therapeutic clown in a pediatric health care setting. The Therapeutic Clown Program at Sick Kids currently practices the Therapeutic Clown/Child Life model proposed here. Therapeutic clowns are most effective when they are specifically trained to work in health care settings, and when they function as members of the health care team, either under or working closely with the Child Life department. Ultimately, the professional clown working with therapeutic intent, no matter what the model, offers to the child a supportive, empowering relationship and opportunities for play and laughter in imaginative and safe play worlds. The creation of these valuable play spaces is made possible through the unique relationships established between clowns and hospitalized children.

\section{Acknowledgments}

We acknowledge the support of Joan Barrington, Coordinator, Therapeutic Clown Program at Sick Kids in the writing of this article, and the Palliative and Bereavement Care Service at Sick Kids. We also thank Lucia Cino, Therapeutic Clown, for her assistance in developing and administering the clown surveys.

\section{Supplementary Data}

Supplementary data are available at eCAM online.

\section{References}

1. Gryski C. Creating the magic circle: the child and the clown in the pediatric healthcare setting [master's research paper]. Ontario Institute for Studies in Education/University of Toronto. Unpublished 2002.

2. Ridd K. There ought to be clowns: child life therapy through the medium of a clown. Unpublished paper 1987.

3. Schwebke S, Gryski C. Gravity and levity - pain and play. In: Klein AJ (ed). Humor in Children's Lives. Westport (CT): Praeger, 2003, pp. 49-68.

4. Towsen J. Clowns. New York: Hawthorn Books, 1976.

5. Hoyle G. The Fool Show [program notes]. Bayview Playhouse, Toronto, 1989.

6. Henderson J. Philosophy of clown. 2005 [cited August 16, 2005]. Available from: www.foolmoon.org/clown_mask_philosophy_ of_clown.htm.

7. Cline P. Fools, Clowns and Jesters. La Jolla: Green Tiger Press, 1983.

8. Tedeschi B. Send in the clowns. Hope Magazine 1998;14:56-63.

9. Simonds C, Warren B. The Clown Doctor Chronicles. Amsterdam, New York: Rodopi, 2004.

10. Warren B. Treating wellness: how clown doctors help to humanize health care and promote good health. In: Twohig P (ed). Making Sense of Health, Illness and Disease. Amsterdam, New York: Rodopi, 2004, 201-16.

11. Herring R. The clown or contrary figure as a counseling intervention strategy with Native American Indian clients. J Multicult Couns Devel 1994;22:153-64.

12. Wright B. Clowns of the Hopi. Flagstaff (AZ): Northland, 1994.

13. Van Blerkom L. Clown doctors: shaman healers of western medicine. Med Anthropol Q 1995;9:462-75.

14. Williams L. Treating the funny bone. Time 1990;136:17-20.

15. Fools for Health [homepage on the Internet]. Windsor. c2005 [cited June 8, 2005] Available from: http://web2.uwindsor.ca/fools_for_ health/index.html

16. The Canadian Association of Therapeutic Clowns/L'Association Canadienne des Clowns Thérapeutiques (CATC/ACCT) [homepage on the Internet]. [cited October 17, 2006] Available from: http://stw.ryerson.ca/ sgrove/index.htm

17. Grock [Adrien Wettach]. Life's a Lark. London: Heinemann, 1931.

18. Isaacson A. The way of the clown. New Age J 1995;59.

19. Meany A. Learning to be a fool. The Irish Times. 2002 [cited March 29, 2006]. Available from: http://scripts.ireland.com/se...r/features/ 2002/0307/88722148atclown.html

20. Big Apple Circus Clown Care Unit. Medical effects of Big Apple Circus Clown Care Unit to be studied by Columbia University's College of Physicians and Surgeons [press release]. Hospital Clown Newsletter. 1996;1(3:2).

21. Disher MW. Clowns and Pantomimes. London: Constable, 1925.

22. Koestler A. The Act of Creation. London, Arkana: Penguin, 1989.

23. Provine R. Laughter: A Scientific Investigation. New York: Viking, 2000.

24. McGhee PE. Humor: Its Origin and Development. San Francisco: W.H. Freeman, 1979

25. Cribb A, Bignold S, Ball SJ. Linking the parts: an exemplar of philosophical and practice issues in holistic nursing. J Adv Nurs 1994;20:233-8.

26. Sourkes B. Armfuls of Time: The Psychological Experience of the Child with a Life-Threatening Illness. Pittsburgh: University of Pittsburgh Press, 1995.

27. Schwartzman H. Transformations: The Anthropology of Children's Play. New York: Plenum Press, 1978.

28. Fisher EP. The impact of play on development: a meta-analysis. Play and Culture 1992;5:159-81.

29. Oremland EK, Oremland JD. Protecting the Emotional Development of the Ill Child. The Essence of the Child Life Profession. Madison (CT): Psychosocial Press, 2000.

30. Pederson C. Effect of imagery on children's pain and anxiety during cardiac catheterization. J Pediatr Nurs: Nurs Care Children Families 1995;10:365-75.

31. Thompson RH, Stanford G. Child Life in Hospitals: Theory and Practice. Springfield (IL): Charles Thomas Publisher, 1981.

32. Vessey J, Carlson KL, McGill J. Use of distraction with children during an acute pain experience. Nurs Res 1994;43:369-81. 
33. Bolig R, Fernie D, Klein E. Unstructured play in hospital settings: an internal locus of control rationale. Children's Health Care 1986;15:101-7.

34. Oremland E. Mastering developmental and critical experiences through play and other expressive behaviors in childhood. Children's Health Care 1988;16:150-6.

35. Huizinga J. Homo Ludens. Boston: The Beacon Press, 1955.

36. Oppenheim D, Simonds C, Hartmann O. Clowning on children's wards. Lancet 1997;350:1838-40.

37. Dumont N. L'enfant et la magie en oncologie pédiatrique [The child and pediatric oncology magic]. Pratiques Psychologiques 2002;3:69-77.

38. Slater J, Gorfinkle K, Bagiella E, Tager F, Labinsky E. Child Behavioral Distress During Invasive Oncologic Procedures and Cardiac Catheterization with the Big Apple Circus Clown Care Unit. Columbia University (NY): Rosenthal Center for Complementary and Alternative Medicine, 1998.

39. Smerling AJ, Skolnick E, Bagiella E, Rose C, Labinsky E, Tager F. Perioperative clown therapy for pediatric patients. Anesth Analg 1999; $88: 243-56$.

40. Aquino RG, Bortolucci RZ, Marta IER. Doutores da graca: a crianca fala [Clown doctors: the child talks]. Brazilian $J$ Nursing 2004;3(2). [cited June 16, 2005] Available from: www.uff.br/nepae/ objn302aquinoetal.htm
41. Bennet MP, Lengacher CA. Humor and laughter may influence health: II Complementary therapies and humor in a clinical population. Evid Based Alternat Complement Med 2006;3:187-90.

42. Bennet MP, Lengacher CA. Humor and laughter may influence health. I. History and background. Evid Based Alternat Complement Med 2006;3:61-3.

43. Vagnoli L, Caprilli S, Robiglio A, Messeri A. Clown doctors as a treatment for preoperative anxiety in children: a randomized, prospective study. Pediatrics 2005;116:563-7.

44. Caprilli S, Messeri A. Animal-assisted activity at A. Meyer Children's Hospital: a pilot study. Evid Based Complement Alternat Med 2006;3:379-83.

45. Spitzer P. Clown doctors! e-Bility News. 2002 [cited March 8, 2006]. Available from: http://e-bility.com/articles/clowndoctors.shtml

46. Warren B. [homepage on the Internet]. Knowing laughter: what do clown doctors know and how do they learn to do what they do? [cited June 8, 2005]. Available from: http://www.oise.utoronto.ca/ depts/sese/csew/nall/res/43knowinglaughter.htm

Received March 24, 2006; accepted March 3, 2007 


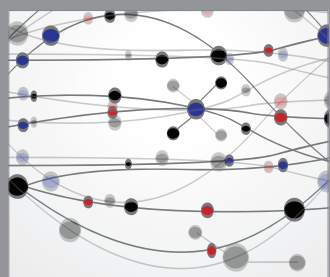

The Scientific World Journal
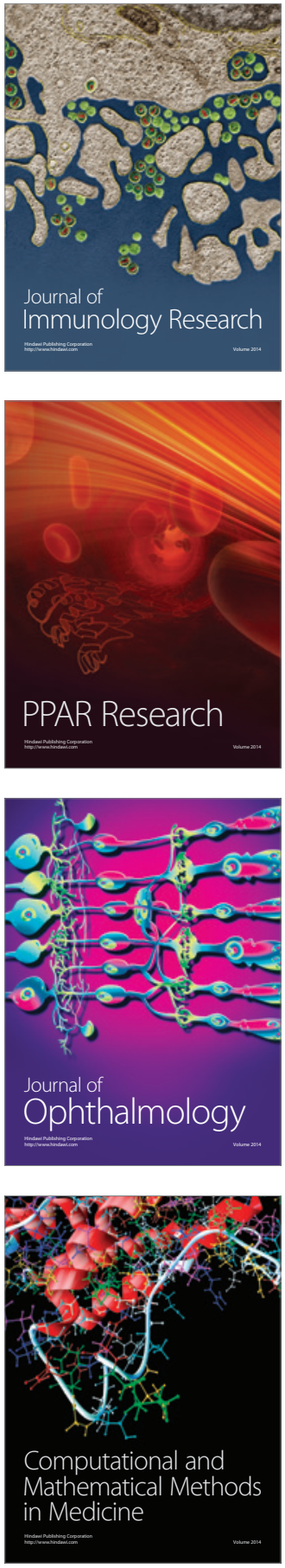

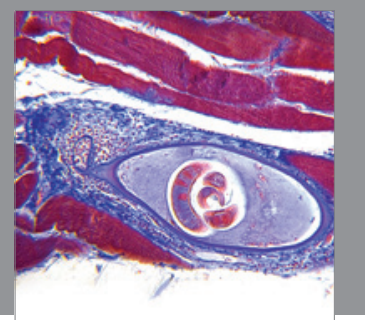

Gastroenterology

Research and Practice
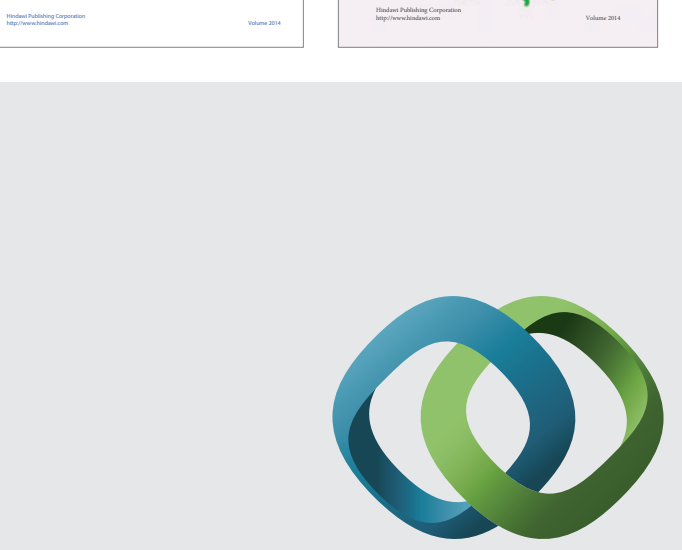

\section{Hindawi}

Submit your manuscripts at

http://www.hindawi.com
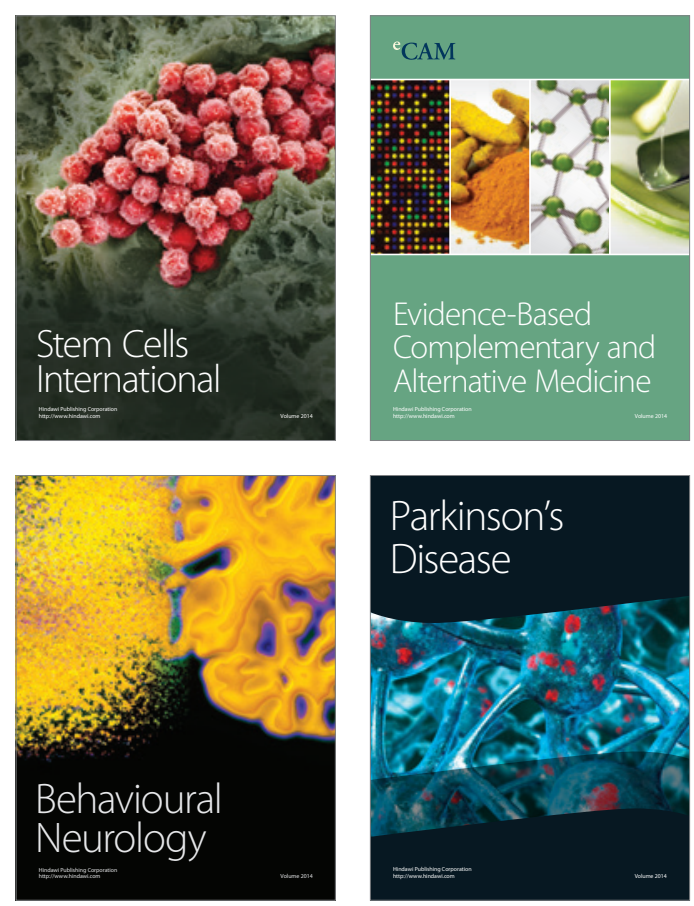

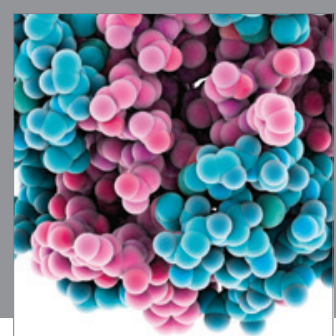

Journal of
Diabetes Research

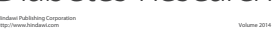

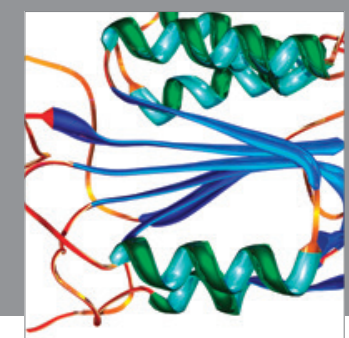

Disease Markers
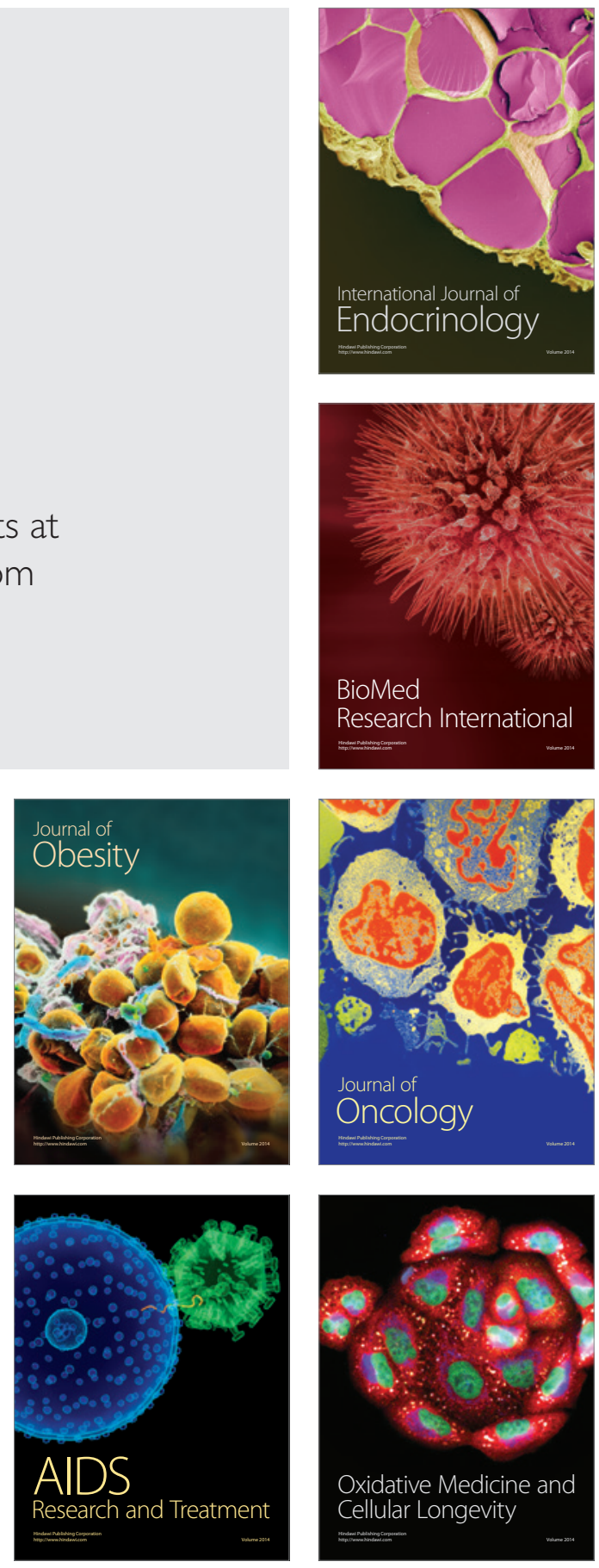